\title{
Next-generation sequencing of tyrosine kinase inhibitor-resistant non-small-cell lung cancers in patients harboring epidermal growth factor-activating mutations
}

Katsuhiro Masago ${ }^{1 *}$, Shiro Fujita ${ }^{1}$, Miho Muraki ${ }^{2}$, Akito Hata ${ }^{1}$, Chiyuki Okuda ${ }^{1}$, Kyoko Otsuka ${ }^{1}$, Reiko Kaji ${ }^{1}$, Jumpei Takeshita ${ }^{1}$, Ryoji Kato ${ }^{1}$, Nobuyuki Katakami ${ }^{1}$ and Yukio Hirata ${ }^{1}$

\begin{abstract}
Background: The aim of this study was to detect the epidermal growth factor receptor (EGFR)-activating mutations and other oncogene alterations in patients with non-small-cell lung cancers (NSCLC) who experienced a treatment failure in response to EGFR-tyrosine kinase inhibitors (TKIs) with a next generation sequencer.

Methods: Fifteen patients with advanced NSCLC previously treated with EGFR-TKls were examined between August 2005 and October 2014. For each case, new biopsies were performed, followed by DNA sequencing on an lon Torrent Personal Genome Machine (PGM) system using the lon AmpliSeq Cancer Hotspot Panel version 2.

Results: All 15 patients were diagnosed with NSCLC harboring EGFR-activating mutations (seven cases of exon 19 deletion, seven cases of L858R in exon 21, and one case of L861Q in exon 21). Of the 15 cases, acquired T790M resistance mutations were detected in $9(60.0 \%)$ patients. In addition, other mutations were identified outside of EGFR, including 13 cases (86.7 \%) exhibiting TP53 P72R mutations, 5 cases (33.3\%) of KDR Q472H, and 2 cases (13.3\%) of KIT M541L.

Conclusions: Here, we showed that next-generation sequencing (NGS) is able to detect EGFR T790M mutations in cases not readily diagnosed by other conventional methods. Significant differences in the degree of EGFR T790M and other EGFR-activating mutations may be indicative of the heterogeneity of disease phenotype evident within these patients. The co-existence of known oncogenic mutations within each of these patients may play a role in acquired EGFR-TKIs resistance, suggesting the need for alternative treatment strategies, with PCR-based NGS playing an important role in disease diagnosis.
\end{abstract}

Keywords: Acquired resistance, Epidermal growth factor, Next-generation sequencing, Tyrosine kinase inhibitor

\footnotetext{
*Correspondence: masago@fbri.org

${ }^{1}$ Division of Integrated Oncology, Institute of Biomedical Research and Innovation, 2-2 Minatojima-minamimachi, Cyuo-ku, Kobe City, Hyogo 650-0047, Japan

Full list of author information is available at the end of the article
}

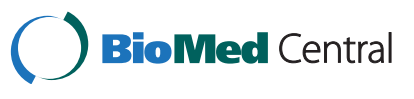

(c) 2015 Masago et al. Open Access This article is distributed under the terms of the Creative Commons Attribution 4.0 International License (http://creativecommons.org/licenses/by/4.0/), which permits unrestricted use, distribution, and reproduction in any medium, provided you give appropriate credit to the original author(s) and the source, provide a link to the Creative Commons license, and indicate if changes were made. The Creative Commons Public Domain Dedication waiver (http://creativecommons.org/publicdomain/zero/1.0/) applies to the data made available in this article, unless otherwise stated. 


\section{Background}

Recent advances in biomedical research have provided a greater understanding of the molecular basis of disease, with significant implications for therapeutic intervention. Somatic mutations, such as epidermal growth factor receptor (EGFR) mutations and anaplastic lymphoma kinase (ALK) gene rearrangements, play a significant role in the pathogenesis of non-small-cell lung cancer (NSCLC), with treatment decisions often based upon the outcome of these genetic tests [1-5].

Both EGFR and $A L K$ function as a receptor tyrosine kinase, which are readily inhibited by a series of tyrosine kinase inhibitors (TKI), including gefitinib [6], erlotinib [7], and crizotinib [2]. Despite the initial treatment efficacy of these TKIs for the treatment of NSCLC, acquired resistance was found to develop in almost all cases. The wellknown mechanism of acquired EGFR-TKIs resistance include second site mutations within the EGFR kinase domain $[8,9]$, up-regulation of alternative signaling pathways, such as $M E T$ [10], histologic transformation, epithelial to mesenchymal transition, and small cell transformation [11]. Although many resistance mechanisms have been clarified, the EGFR kinase domain mutation T790M in exon 20 accounts for nearly half of all acquired resistance, making testing for this mutation a key factor in determining following treatment strategies in the era of second- and thirdgeneration EGFR-TKIs $[12,13]$.

The recent development of next-generation sequencing (NGS) as a diagnostic tool in the clinical setting has enabled us to determine rapid, targeted sequencing of tumors for causative mutations. When combined with various selective capture approaches, NGS has allowed for the efficient simultaneous genetic analysis of a large number of candidate genes. Here, we applied a polymerase chain reaction (PCR) based NGS in determining oncogene alternations in the state of disease progression.

PCR based next-generation sequencing is an outstanding tool to provide a comprehensive genomic diagnosis in patients with recurrent NSCLC [14]. The primary aim of this study was to evaluate $E F G R$ T790M secondary mutations, along with other oncogenic alterations, in NSCLC patients previously diagnosed with EGFR activating mutations who experienced disease recurrence after treatment with first-generation EGFR-TKIs.

\section{Methods}

\section{Patients and treatment regimens}

Fifteen patients with NSCLC previously treated with EGFR-TKIs were examined between August 2005 and October 2014 at the Institute of Biomedical Research and Innovation in Kobe City, Japan. Patients were treated with either of erlotinib or gefitinib daily, at initial daily doses of 150 (erlotinib) and 250 (gefitinib) mg/day. Standard
Response Evaluation Criteria in Solid Tumors (RECIST 1.0) was used to evaluate treatment response. Toxicities were graded according to the Common Terminology Criteria for Adverse Events (CTCAE) version 4.0. We obtained written informed consents from all the participants. This study was approved by the Research Ethics Committee of the Institute of Biomedical Research and Innovation.

\section{EGFR mutational analysis}

A quantity of cancer cells sufficient for a pathologic diagnosis (i.e., several hundred cells) were obtained from formalin-fixed paraffin-embedded (FFPE) biopsy specimens by manual micro-dissection. Similar biopsy specimens were used to analyze EGFR somatic mutations in exons $18-21[15,16]$.

\section{MET gene amplification}

For each patient, DNA was extracted, and the concentration measured using a Nanodrop ND-1000 spectrophotometer (Nanodrop Technologies, Rockland, DE). MET copy number gains (CNG) analysis was performed using the One-Step Real Time PCR System (Thermo Fisher Scientific, Foster City, CA) under the following conditions: one cycle of $95{ }^{\circ} \mathrm{C}$ for $10 \mathrm{~min}$ followed by 40 cycles of $95{ }^{\circ} \mathrm{C}$ for $15 \mathrm{~s}$ and $60^{\circ} \mathrm{C}$ for $1 \mathrm{~min}$. The qPCR reaction mixture contained $10 \mu \mathrm{L}$ of $2 \mathrm{X}$ TaqMan genotyping master mix, $1 \mu \mathrm{L}$ of the TaqMan copy number target assay, $1 \mu \mathrm{L}$ of the TaqMan copy number reference assay (RNase P, which is known to exist only in two copies in a diploid genome), $4 \mu \mathrm{L}$ of nuclease-free water, and $4 \mu \mathrm{L}$ of DNA (diluted to a concentration of $5 \mathrm{ng} / \mu \mathrm{L}$ ). Each sample was run in a minimum of four replicates. Amplification results were then analyzed using the CopyCaller Software (Thermo Fisher Scientific) for post-PCR data analysis. To accurately detect $M E T$ CNG, we analyzed the previous reported region of $M E T$ [17], a region spanning the intron 20-exon 21 boundary (TaqMan copy number assay Hs02884964_cn).

\section{Ion torrent PGM library preparation and sequencing}

An Ion Torrent adapter-ligated library was generated using an Ion AmpliSeq Library Kit 2.0 according to the manufacturer's protocol (Thermo Fisher Scientific, Rev. 5; MAN0006735). Briefly, $50 \mathrm{ng}$ of pooled amplicons and the Ion AmpliSeq Cancer Hotspot Panel version 2 (Thermo Fisher Scientific) were end-repaired, and Ion Torrent adapters P1 and A were ligated using DNA ligase. Following AMPure bead (Beckman Coulter, Brea, CA, USA) purification, the concentration and size of the library were determined using the Life Technologies StepOne system (Thermo Fisher Scientific) and Ion Library TaqMan quantitation assay kit (Thermo Fisher Scientific). Sample emulsion PCR, emulsion breaking, and enrichment were 
performed using the Ion PGM IC 200 Kit (Thermo Fisher Scientific), according to the manufacturer's instructions. Briefly, an input concentration of one DNA template copy/Ion Sphere Particle (ISP) was added to the emulsion PCR master mix, and the emulsion was generated using the Ion Chef (Thermo Fisher Scientific). Next, ISPs were recovered and template-positive ISPs enriched using Dynabeads MyOne Streptavidin C1 beads (Thermo Fisher Scientific). Sequencing was undertaken using 314 BC chips on the Ion Torrent PGM for 65 cycles using barcoded samples. The totally turnaround time from library preparation to the end of sequencing is about 2 days.

\section{Variant calling}

After sequencing, data were processed using the Ion Torrent platform-specific pipeline software Torrent Suite to generate sequence reads, trim adapter sequences, and remove poor signal-profile reads. Initial variant calling was generated using Torrent Suite Software v4.0 using the variant caller plug-in. To eliminate erroneous base calling, three filtering steps were used. The first filter was set at an average total coverage depth of $>100$, variant coverage of $>20$, and $P$ values $<0.01$. The second filter was employed by visually examining mutations using the Integrative Genomics Viewer (http//www.broadinstitute.org/igv) or CLC Genomics Workbench version 7.04 (Qiagen) software. Finally, possible strand-specific errors, such as mutation only detected in only the plus or minus strand were removed.

\section{Results}

A summary of patient characteristics can be found in Table 1. All patients were Japanese, consisting of $10 \mathrm{fe}-$ males $(76.7 \%)$ and 5 males (33.3 \%). Nine patients (60.0\%) were never smokers, and the remaining six patients $(40.0 \%)$ were former smokers. All patients had stage IV adenocarcinoma, as defined based upon TNM classification criteria (7th edition) [18]. Eight patients received erlotinib, and four patients were treated with gefitinib. The remaining patient was treated first with gefitinib, then switched to erlotinib. The median duration of EGFR-TKI therapy was 510 days (range: 122-1912 days; Table 1).

EGFR sequence variations are listed in Table 2. All patients were diagnosed with adenocarcinomas harboring EGFR activating mutations (seven cases of exon 19 deletion, seven cases of L858R in exon 21, and one case of L861Q in exon 21). Of the 15 cases, acquired EGFR T790M resistance mutations in exon 20 were detected in $9(60.0 \%)$ patients. Of particular interest were cases 7, 8 , and 10, in which T790M mutations were not detected by high-sensitivity conventional PCR-based methods, such as peptide nucleic acid-locked nucleic acid (PNA-LNA) PCR clamp [16], or Cycleave real-time PCR [15].
Table 1 Patient characteristics

\begin{tabular}{ll}
\hline Patient characteristics & $(\%)$ \\
\hline $\begin{array}{l}\text { Age (years) } \\
\text { Range }\end{array}$ & $54-79$ \\
$\begin{array}{l}\text { Gender } \\
\text { Male }\end{array}$ & $5(33.3)$ \\
$\quad$ Female & $10(76.7)$ \\
Smoking status & \\
$\quad$ Non-smoker & $9(60.0)$ \\
$\quad$ Former Smoker & $6(40.0)$ \\
Stage & \\
$\quad$ V & $14(93.4)$ \\
$\quad$ rlV & $1(6.6)$ \\
$1^{\text {st }}$ line & $5(33.3)$ \\
$2^{\text {nd }}$ line & $7(46.7)$ \\
$3^{\text {rd }}$ line & $2(13.4)$ \\
Subsequent therapy & $1(6.6)$ \\
\hline
\end{tabular}

${ }^{\mathrm{a}} \mathrm{r} I V$ recurrent stage IV

In addition to T790M mutations, a large number of activating mutations were identified outside of EGFR. $M E T$ amplification, another common mutation associated with EGFR-TKI resistance, was not seen (Fig. 1), which is also confirmed by copy number analysis of NGS sequencing data (data not shown). Further screening of an additional 50 known oncogenes revealed a quite number of mutations in at least 32 genes (Table 3), including 13 cases $(86.7 \%)$ of TP53 P72R mutations, 5 cases (33.3 \%) of KDR Q472H, and 2 cases (13.3\%) of KIT M541L. A full list of genes analyzed in this study is shown in Table 4.

\section{Discussion}

In this study we analyzed biopsy specimens of patients who underwent second biopsy after treatment failure with the first generation EGFR-TKIs. There was a significant difference between the frequency of EGFR T790M and other $E G F R$-activating mutations, with significant variability among cases (4.8-41.3\%). The existence of EGFR and other mutations within the same tumor sample identified by NGS highlights the importance of this type of analysis in guiding appropriate cancer therapy.

High-throughput sequencing was able to detect T790M mutation in a number of cases with the same accuracy of conventional highly sensitive conventional PCR methods, such as PNA-LNA PCR clamp [16] and Cycleave real-time PCR [15]. While high sensitivity and specificity of these methods is well established [19-27], the use of NGS provides important advantages with clarifying activating mutation rate in tumor sample as well as greater detection of rare mutations outside of 
Table 2 Clinical characteristics and next-generation sequencing results

\begin{tabular}{|c|c|c|c|c|c|c|c|c|c|}
\hline & Histology & $\begin{array}{l}\text { EGFR Sequence } \\
\text { Variants }\end{array}$ & $\begin{array}{l}\text { Frequency } \\
(\%)\end{array}$ & Allele Call & $\begin{array}{l}\text { Exon } 20 \\
\text { T790M }\end{array}$ & $\begin{array}{l}\text { Frequency } \\
(\%)\end{array}$ & $\begin{array}{l}\text { Conversion } \\
\text { to SCLC }\end{array}$ & Prior TKls & $\begin{array}{l}\text { Duration } \\
\text { (days) }\end{array}$ \\
\hline \multirow[t]{2}{*}{ Case 1} & Adenocarcinoma & Exon 19 & 44.3 & Heterozygous & Yes & 7.2 & No & Erlotinib & 681 \\
\hline & & E746_T750 del & & & & & & & \\
\hline \multirow[t]{2}{*}{ Case 2} & Adenocarcinoma & Exon 19 & 59.4 & Heterozygous & No & - & No & Gefitinib & 537 \\
\hline & & E746_T751 del > A & & & & & & & \\
\hline \multirow[t]{2}{*}{ Case 3} & Adenocarcinoma & Exon 21 L858R & 46.1 & Heterozygous & No & - & No & Gefitinib & 195 \\
\hline & & Exon $18 \mathrm{~T} 725 \mathrm{R}$ & 30.6 & Heterozygous & & & & & \\
\hline \multirow[t]{2}{*}{ Case 4} & Adenocarcinoma & Exon 21 L858R & 23.3 & Heterozygous & No & - & No & Erlotinib & 217 \\
\hline & & Exon $20 \mathrm{S7681}$ & 10.0 & Heterozygous & & & & & \\
\hline \multirow[t]{2}{*}{ Case 5} & Adenocarcinoma & Exon21 L858R & 56.9 & Heterozygous & No & - & No & Gefitinib & 1105 \\
\hline & & Exon 18 E709G & 54.5 & Heterozygous & & & & & \\
\hline \multirow[t]{2}{*}{ Case 6} & Adenocarcinoma & Exon 19 & 97.2 & Homozygous & Yes & 21.8 & No & Erlotinib & 693 \\
\hline & & E746_T750 del & & & & & & & \\
\hline Case 7 & Adenocarcinoma & Exon 21 L858R & 13.8 & Heterozygous & Yes & 5.2 & No & Erlotinib & 537 \\
\hline \multirow[t]{2}{*}{ Case 8} & Squamous cell carcinoma & Exon 19 & 86.9 & Heterozygous & Yes & 7.3 & No & Erlotinib & 315 \\
\hline & & E746_T750 del & & & & & & & \\
\hline \multirow[t]{2}{*}{ Case 9} & Adenocarcinoma & Exon 19 & 65.3 & Heterozygous & Yes & 41.3 & No & Erlotinib & 1555 \\
\hline & & E746_T750 del & & & & & & & \\
\hline Case 10 & Adenocarcinoma & Exon21 L858R & 11.2 & Heterozygous & Yes & 4.8 & No & Gefitinib & 1912 \\
\hline \multirow[t]{2}{*}{ Case 11} & Adenocarcinoma & Exon 19 & 46.4 & Heterozygous & Yes & 11.0 & No & Erlotinib & 256 \\
\hline & & E746_T750 del & & & & & & & \\
\hline \multirow[t]{2}{*}{ Case 12} & Adenocarcinoma & Exon21 L858R & 22.2 & Heterozygous & No & - & No & Erlotinib & 924 \\
\hline & & Exon $21 \mathrm{G} 873 \mathrm{R}$ & 10.8 & Heterozygous & & & & & \\
\hline \multirow[t]{4}{*}{ Case 13} & Adenocarcinoma & Exon $21 \mathrm{~L} 861 \mathrm{Q}$ & 59.9 & Heterozygous & No & - & No & Gefitinib Erlotinib & 1304122 \\
\hline & & Exon 20 P772S & 10.2 & Heterozygous & & & & & \\
\hline & & Exon19 L747S & 11.8 & Heterozygous & & & & & \\
\hline & & Exon2 A289V & 12.3 & Heterozygous & & & & & \\
\hline \multirow[t]{2}{*}{ Case 14} & Adenocarcinoma & Exon 19 & 80.82 & Heterozygous & Yes & 14.8 & No & Erlotinib & 392 \\
\hline & & E746_T750 del & & & & & & & \\
\hline Case 15 & Adenocarcinoma & Exon21 L858R & 76.7 & Heterozygous & Yes & 10.3 & No & Erlotinib & 339 \\
\hline
\end{tabular}

target areas [28-31]. In addition, to emphasize the power of NGS in clinical practice, we should also try to develop its applications and usages such as challenging specimens or testing processes, such as peripheral blood in the future.

NGS is also able to overcome issue of germ-line DNA contamination, similar to that of new PCR methods, such as digital PCR [32]. This tolerance of germ-line DNA contamination allows for more streamlined sample preparation techniques, without need for time-consuming procedures such as macro- or micro-dissection. In this study, all samples were extracted from FFPE biopsy specimens, highlighting both versatility and potential use of NGS in clinical settings. Furthermore NGS is able to quantify gene mutations within a tumor sample. Due to the unpredictablity of PCR amplification and germ line DNA contamination, observed mutations does not always reflect the penetrance of a mutation within a sample. While most highly sensitive detection methods provide only categorical results such as positive and negative, our analysis was able to identify the degree of EGFR T790M and other EGFR-activating mutations within a sample that could not be explained by germ-line DNA contamination and/or PCR efficacy. These results are consistent with previous reports detailing T790M allelic frequency in terms of both intra-tumor heterogeneity in localized lung adenocarcinomas [33] and allelic imbalances [34]. Our analysis was able to identify the degree of EGFR T790M and other EGFR-activating mutations within a sample that could not be explained by germ-line DNA contamination and/or PCR efficacy. Future treatment with next-generation EGFR-TKIs targeting T790M is likely to be informed by such analyses, as 


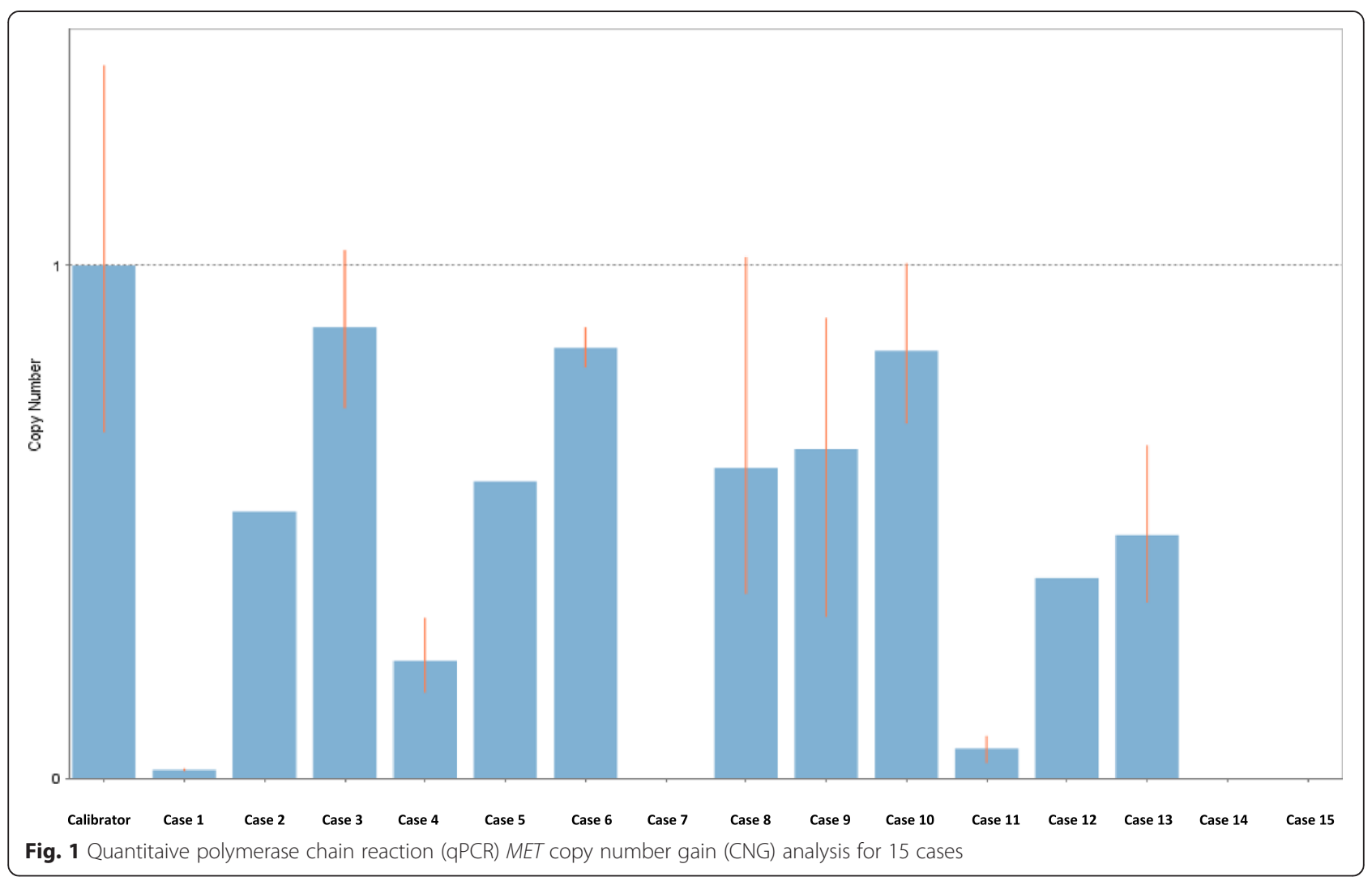

patients should be treated based upon their EGFR acquired mutation [35].

In addition to EGFR mutations, we also evaluated another 50 oncogenes thought to have an important role in cancer pathogenesis (Table 4). A large number of mutations were identified in this analysis. However, how much extent these genes affect tumorigenicity, tumor progression, and resistance to EGFR-TKIs is difficult to assess, as some mutations may represent only passive alterations (passenger mutations). Although many of these mutations were identified in a single patient, a series of mutations including TP53 P72R, KDR Q472R, and KIT M541L were detected in more than two cases, suggesting a role in disease progression.

TP53 P72R was the most common mutation, detected in 13 of 15 cases $(86.7 \%)$. In human populations, TP53 codon 72 is encoded by the nucleotide sequence CCC, which encodes proline, or CGC, which encodes arginine. While proline is the most common amino acid found at this residue, comparative sequence analyses have detected a high degree (>50 \%) of TP53-R72 variants among certain populations [36]. The current understanding of TP53 biology is that TP53-R72 is more effective at inducing apoptosis and protecting stressed cells from neoplastic development than the more common TP53-P72 [37]. However, it is not yet understood how these functional differences might translate between in vitro and in vivo settings [38, 39], making it difficult to assess the role of this sequence variant of EGFR-TKI resistance.

$K D R$ (kinase insert domain receptor, also known as VEGFR2) is an important factor in tumor development and progression due to its pro-angiogenic effects [40]. KDR Q472H mutations were detected in 5 of 15 cases (33.3\%), making it the second most common gene variant observed outside of EGFR. In human populations, codon 472 of KDR is encoded by the nucleotide sequence CAA, which encodes glutamine, or CAT, which encodes histidine. The Q472H variant is thought to affect protein function due to increased phosphorylation after vascular endothelial growth factor (VEGF)-A stimulation, along with increased binding efficiency for VEGF-A165 [41]. The effect of $\mathrm{Q} 472 \mathrm{H}$ on microvessel density is thought to occur as a result of increased phosphorylation of VEGFR2 [42]. Here, increased microvessel density may have contributed to EGFR-TKI resistance, suggesting that VEGFR2 inhibition may inhibition may become an important therapeutic option in patients with documented EGFR-TKI resistance.

V-Kit Hardy-Zuckerman 4 Feline Sarcoma Viral Oncogene Homolog (KIT) M541L substitutions were detected in 2 of 15 cases $(13.3 \%)$. c-KIT is one of the primary targets of imatinib, and mutations in KIT are predictive of the efficacy of the drug in gastrointestinal stromal tumors (GIST) [43]. Several case reports have suggested 
Table 3 Coexisting somatic mutations resulting in amino-acid changes identified using the lon AmpliSeq Hotspot Panel version 2

\begin{tabular}{|c|c|c|c|c|c|c|c|c|c|c|}
\hline & & $\begin{array}{l}\text { Frequency } \\
(\%)\end{array}$ & & $\begin{array}{l}\text { Frequency } \\
(\%)\end{array}$ & & $\begin{array}{l}\text { Frequency } \\
(\%)\end{array}$ & & $\begin{array}{l}\text { Frequency } \\
(\%)\end{array}$ & & $\begin{array}{l}\text { Frequency } \\
(\%)\end{array}$ \\
\hline Case 1 & KIT M541L (COSM 28026) & 70.9 & TP53 P72R & 53.2 & - & - & - & - & - & - \\
\hline Case 2 & PTEN L57W (COSM 5253) & 21.2 & - & - & - & - & - & - & - & - \\
\hline Case 3 & TP53 P72R & 57.0 & $\begin{array}{l}\text { CTNNB1 D32N } \\
\text { (COSM 5672) }\end{array}$ & 34.5 & TP53 V73 del & 29.1 & CDH1 Q346* (COSM 19524) & 25.1 & - & - \\
\hline Case 4 & TP53 P72R & 60.3 & $\begin{array}{l}\text { TP53 R337C } \\
\text { (COSM 11071) }\end{array}$ & 18.0 & - & - & - & - & - & - \\
\hline Case 5 & TP53 P72R & 46.9 & $K D R \mathrm{Q} 472 \mathrm{H}$ & 46.9 & KIT G534C & 46.3 & APC S1463fs & 42.5 & - & - \\
\hline \multirow[t]{3}{*}{ Case 6} & PDGFRA P567Q & 100 & TP53 V73W & 72.6 & TP53 P151S & 57.5 & $K D R \mathrm{Q} 472 \mathrm{H}$ & 42.4 & ERBB4 C614Y & 38.2 \\
\hline & SMAD4 R189H & 29.0 & PTEN R233Q & 18.5 & APC D1591N & 18.4 & HRAS T64* & 17.9 & AKT1 T21I & 16.4 \\
\hline & KIT L647F & 16.2 & SKT11 D352N & 15.1 & PTEN H123Y (COSM 5078) & 7.3 & PTEN R130Q (COSM 5033) & 7.2 & - & - \\
\hline Case 7 & TP53 P72R & 96.7 & SKT11 F345L & 53.5 & SKT11 P281L & 53.3 & $K D R \mathrm{Q} 472 \mathrm{H}$ & 42.6 & - & - \\
\hline \multirow[t]{4}{*}{ Case 8} & TP53 P72R & 98.4 & $\begin{array}{l}\text { KIT M541L } \\
\text { (COSM 28026) }\end{array}$ & 59.8 & TP53 V154G (COSM 43903) & 35.4 & $K D R \mathrm{Q} 472 \mathrm{H}$ & 26.7 & SMAD4 G423R & 14.7 \\
\hline & $A B L 1$ 1347fs & 11.1 & ERBB4 C759T & 8.8 & FBXW7 M467l & 8.0 & MLH1 A169V & 8.0 & KDR G1284R & 7.9 \\
\hline & APC P1433L & 6.7 & TP53 F338L & 6.5 & SMO P610S & 6.4 & MET D340A & 5.8 & NOTCH1 V1575M & 5.7 \\
\hline & PTEN A328E & 5.6 & $\begin{array}{l}\text { APC G1374K } \\
\text { (COSM 18737) }\end{array}$ & 5.1 & MLH1 R148W & 5.0 & - & - & - & - \\
\hline Case 9 & APC E1464fs & 59.2 & TP53 P72R & 48.2 & BRAF G442D & 6.1 & MET G1102D & 5.5 & SMO T2231 & 5.0 \\
\hline Case 10 & MET N375K & 55.7 & TP53 P72R & 42.0 & CTNNB1 G34V & 6.5 & - & - & - & - \\
\hline Case 11 & TP53 P72R & 68.5 & $\begin{array}{l}\text { PTEN N329fs } \\
\text { (COSM 4932) }\end{array}$ & 39.5 & TP53 K132R (COSM 11582) & 29.7 & - & - & - & - \\
\hline \multirow[t]{2}{*}{ Case 12} & TP53 P72R & 98.1 & KDR Q472H & 96.4 & TP53 V272fs & 21.0 & RB1 I682T & 12.6 & APC P1433L & 9.6 \\
\hline & RET E884V & 9.1 & SMAD4 V354L & 8.0 & - & - & - & - & - & - \\
\hline \multirow[t]{6}{*}{ Case 13} & TP53 P72R & 99.1 & CDKN2 G155S & 51.6 & FLT3 W603* & 45.2 & KRAS E37K & 33.3 & SMO P641L & 23.7 \\
\hline & IDH1 L103M & 20.0 & $\begin{array}{l}\text { TP53 R267Q } \\
\text { (COSM 43923) }\end{array}$ & 18.8 & GNA11 D205N & 16.2 & SMARCB1 P165S & 14.0 & RB1 M761T & 13.9 \\
\hline & SMARCB1 V145L & 12.4 & $\begin{array}{l}\text { TP53 G245R } \\
\text { (COSM 10957) }\end{array}$ & 10.8 & NOTCH1 H1591T & 10.7 & ERBB4 G240V & 10.0 & KIT S715N & 9.9 \\
\hline & FBXW7 R505H (COSM 25812) & 9.8 & FBXW7 M498I & 9.2 & MET S186L & 8.8 & IDH1 A111V & 8.8 & $J A C 3 \vee 133 \mid$ & 8.5 \\
\hline & KIT V825I (COSM 19110) & 8.1 & TP53 G112S & 6.5 & TP53 K132E (COSM 10813) & 6.3 & HNF1A A193V & 6.3 & VHL K171T & 5.7 \\
\hline & ALK P1191A & 5.6 & HNF1A T204I & 5.3 & - & - & - & - & - & - \\
\hline Case 14 & PTEN H1047L & 62.9 & FGFR3 R765S & 7.2 & IDH1 P118L & 5.7 & - & - & - & - \\
\hline Case 15 & TP53 P72R & 100 & MET A179M & 5.1 & - & - & - & - & - & - \\
\hline
\end{tabular}


Table 4 Target genes in the Ion AmpliSeq Hotspot Panel

\begin{tabular}{llll} 
version 2 & & & \\
\hline ABL1 & EZH2 & JAK3 & PTEN \\
AKT1 & FBXW7 & IDH2 & PTPN11 \\
ALK & FGFR1 & KDR & RB1 \\
APC & FGFR2 & KIT & RET \\
ATM & FGFR3 & KRAS & SMAD4 \\
BRAF & FLT3 & MET & SMARCB1 \\
CDH1 & GNA11 & MLH1 & SMO \\
CDKN2A & GNAS & MPL & SRC \\
CSF1R & GNAQ & NOTCH1 & STK11 \\
CTNNB1 & HNF1A & NPM1 & TP53 \\
EGFR & HRAS & NRAS & VHL \\
ERBB2 & IDH1 & PDGFRA & \\
ERBB4 & JAK2 & PIK3CA & \\
\hline
\end{tabular}

a potential role of the KIT M541L variant in the sensitivity of Imatinib for aggressive fibromatosis [44-46]. Furthermore, a wide array of in vitro analyses support a role for the L541 variant in tumorigenesis. FDC-P1 cells transfected with KIT-L541 showed an enhanced proliferative response, while KIT-L541 cells were more sensitive to imatinib than those expressing wild-type $K I T$ [47]. Inokuchi, et al. observed a higher frequency of L541 variants among patients with chronic myelogenous leukemia (CML), which is consistent with increased tyrosine kinase activation and proliferative responses in KIT-L541 cells relative to wild-type controls [48]. From the view point of EGFR-TKI resistance, these data suggest a causative role for the KIT L541 variant in recurrence and drug resistance of NSCLC. Suppression of KIT with drugs like Imatinib may be a useful therapeutic choice in patients with $K I T$-variant tumors.

Five (cases 3, 4, 5, 12 and 13) out of six NSCLC patients that are negative for EGFR-T790M mutation harbored "compound mutations" (a rare EGFR mutation in combination with a more frequent activating mutation). On the other hand, all T790M-positive tumors (cases 1, 6, 7, 8, 9, 10 and 11) lack an additional rare mutation apart from the presence of a frequent inhibitor-sensitive EGFR mutation. Among these compound mutations (specifically rare mutations), tumors harboring S768I in exon 20 is known as resistant to EGFR-TKIs. On the contrary, tumors harboring point mutations in exon 18 and dual mutation of exon 19 deletion and S768I are reported to possible response to EGFR-TKIs. There have been limited data in other compounds mutations. So a role of these mutations in causing drug resistance in T790M-negative patients is uncertain and need to be evaluated [49].

This study has its limitations. The strongest limitations include a small sample size, and the retrospective nature of the study preventing the comparison of our findings to non-lesional or pre-treatment results. With this limitation of not having pre-treatment results, the role of activating mutations in additional oncogenes in TKI-resistance may be the primary cause for TKI resistance especially in the case of $K D R \mathrm{Q} 472 \mathrm{H}$ mutations. A larger prospective study with strict enrollment criteria is definitely needed to overcome these limitations.

\section{Conclusion}

In conclusion, our study showed that NGS could be useful to detect EGFR T790M variants in patients not otherwise found with other conventional PCR based methods. Furthermore, our results highlight the difference of the extent of EGFR T790M and other EGFR-activating mutations among tumor samples, which may indicate the heterogeneity of acquired mutations. Identification of additional sequence variations in potential oncogenes that may affect EGFR-TKI resistance would suggest a series of new therapeutic agents targeting on a patient's underlying genetic profile.

\section{Competing interests}

The authors declare that they have no competing financial and non-financial interests.

\section{Authors' contributions}

KM and SF carried out the molecular genetic studies, participated in the sequence alignment and drafted the manuscript. MM gave us some technical information. KM and SF participated in the conception and design of the study and performed the statistical analysis. KM, SF, AH, CO, KO, RK, JT, $\mathrm{RK}, \mathrm{NK}$ and $\mathrm{YH}$ engaged in the acquisition and interpretation of data. KM and SF was involved in drafting the manuscript. KM, SF participated in its design and coordination and helped to draft the manuscript. All authors read and approved the final manuscript.

\section{Author details}

${ }^{1}$ Division of Integrated Oncology, Institute of Biomedical Research and Innovation, 2-2 Minatojima-minamimachi, Cyuo-ku, Kobe City, Hyogo 650-0047, Japan. ${ }^{2}$ Thermo Fisher Scientific, Tokyo, Japan.

Received: 10 February 2015 Accepted: 11 November 2015

Published online: 16 November 2015

\section{References}

1. Shigematsu H, Lin L, Takahashi T, Nomura M, Suzuki M, Wistuba II, et al. Clinical and biological features associated with epidermal growth factor receptor gene mutations in lung cancers. J Natl Cancer Inst. 2005;97(5):339-46.

2. Kwak EL, Bang YJ, Camidge DR, Shaw AT, Solomon B, Maki RG, et al. Anaplastic lymphoma kinase inhibition in non-small-cell lung cancer. N Engl J Med. 2010:363(18):1693-703.

3. Gridelli C, de Marinis F, Cappuzzo F, Di Maio M, Hirsch FR, Mok T, et al. Treatment of advanced non-small-cell lung cancer with Epidermal Growth Factor Receptor (EGFR) mutation or ALK gene rearrangement: results of an international expert panel meeting of the Italian Association of Thoracic Oncology. Clin Lung Cancer. 2014;15(3):173-81.

4. Ulivi P, Zoli W, Capelli L, Chiadini E, Calistri D, Amadori D. Target therapy in NSCLC patients: relevant clinical agents and tumour molecular characterisation. Mol Clin Oncol. 2013;1(4):575-81.

5. Sandler A, Gray R, Perry MC, Brahmer J, Schiller JH, Dowlati A, et al. Paclitaxel-carboplatin alone or with bevacizumab for non-small-cell lung cancer. N Engl J Med. 2006;355(24):2542-50.

6. Thatcher N, Chang A, Parikh P, Rodrigues Pereira J, Ciuleanu T, von Pawel J, et al. Gefitinib plus best supportive care in previously treated patients with refractory advanced non-small-cell lung cancer: results from a randomised, 
placebo-controlled, multicentre study (Iressa Survival Evaluation in Lung Cancer). Lancet. 2005;366(9496):1527-37.

7. Shepherd FA, Rodrigues Pereira J, Ciuleanu T, Tan EH, Hirsh V, Thongprasert S et al. Erlotinib in previously treated non-small-cell lung cancer. N Engl J Med. 2005;353(2):123-32.

8. Balak MN, Gong Y, Riely GJ, Somwar R, Li AR, Zakowski MF, et al. Novel D761Y and common secondary T790M mutations in epidermal growth factor receptor-mutant lung adenocarcinomas with acquired resistance to kinase inhibitors. Clin Cancer Res. 2006;12(21):6494-501.

9. Bean J, Riely GJ, Balak M, Marks JL, Ladanyi M, Miller VA, et al. Acquired resistance to epidermal growth factor receptor kinase inhibitors associated with a novel T854A mutation in a patient with EGFR-mutant lung adenocarcinoma. Clin Cancer Res. 2008:14(22):7519-25.

10. Engelman JA, Zejnullahu $K$, Mitsudomi $T$, Song $Y$, Hyland C, Park JO, et al. MET amplification leads to gefitinib resistance in lung cancer by activating ERBB3 signaling. Science. 2007;316(5827):1039-43.

11. Sequist LV, Waltman BA, Dias-Santagata D, Digumarthy $S$, Turke AB, Fidias $P$, et al. Genotypic and histological evolution of lung cancers acquiring resistance to EGFR inhibitors. Sci Transl Med. 2011;3(75):75ra26.

12. Yu HA, Riely GJ, Lovly CM. Therapeutic strategies utilized in the setting of acquired resistance to EGFR tyrosine kinase inhibitors. Clin Cancer Res. 2014; 20:5898.

13. Stinchcombe TE. Novel agents in development for advanced non-small cell lung cancer. Ther Adv Med Oncol. 2014;6(5):240-53.

14. Yatabe $Y$, Thomas RK. Era of comprehensive cancer genome analyses. J Clin Oncol. 2014;32:4029.

15. Kosaka T, Yatabe Y, Onozato R, Kuwano H, Mitsudomi T. Prognostic implication of EGFR, KRAS, and TP53 gene mutations in a large cohort of Japanese patients with surgically treated lung adenocarcinoma. J Thorac Oncol. 2009:4(1):22-9.

16. Nagai Y, Miyazawa H, Huqun, Tanaka T, Udagawa K, Kato M, et al. Genetic heterogeneity of the epidermal growth factor receptor in non-small cell lung cancer cell lines revealed by a rapid and sensitive detection system, the peptide nucleic acid-locked nucleic acid PCR clamp. Cancer Res. 2005; 65(16):7276-82.

17. Graziano F, Galluccio N, Lorenzini P, Ruzzo A, Canestrari E, D'Emidio S, et al. Genetic activation of the MET pathway and prognosis of patients with highrisk, radically resected gastric cancer. J Clin Oncol. 2011;29(36):4789-95.

18. Goldstraw P, Crowley J, Chansky K, Giroux DJ, Groome PA, Rami-Porta R, et al. The IASLC Lung Cancer Staging Project: proposals for the revision of the TNM stage groupings in the forthcoming (seventh) edition of the TNM Classification of malignant tumours. J Thorac Oncol. 2007:2(8):706-14.

19. Ellison G, Zhu G, Moulis A, Dearden S, Speake G, McCormack R. EGFR mutation testing in lung cancer: a review of available methods and their use for analysis of tumour tissue and cytology samples. J Clin Pathol. 2013; 66(2):79-89.

20. Ohashi K, Maruvka YE, Michor F, Pao W. Epidermal growth factor receptor tyrosine kinase inhibitor-resistant disease. J Clin Oncol. 2013;31(8):1070-80.

21. Watanabe M, Kawaguchi T, Isa SI, Ando M, Tamiya A, Kubo A, et al. Ultrasensitive detection of the pretreatment EGFR T790M mutation in non-smal cell lung cancer patients with an EGFR-activating mutation using droplet digital PCR. Clin Cancer Res. 2015;21:3552.

22. Rosell R, Molina MA, Costa C, Simonetti S, Gimenez-Capitan A, BertranAlamillo J, et al. Pretreatment EGFR T790M mutation and BRCA1 mRNA expression in erlotinib-treated advanced non-small-cell lung cancer patients with EGFR mutations. Clin Cancer Res. 2011;17(5):1160-8.

23. Su KY, Chen HY, Li KC, Kuo ML, Yang JC, Chan WK, et al. Pretreatment epidermal growth factor receptor (EGFR) T790M mutation predicts shorter EGFR tyrosine kinase inhibitor response duration in patients with non-small-cell lung cancer. J Clin Oncol. 2012;30(4):433-40.

24. He Y, Li S, Ren S, Cai W, Li X, Zhao C, et al. Impact of family history of cancer on the incidence of mutation in epidermal growth factor receptor gene in non-small cell lung cancer patients. Lung Cancer. 2013;81(2):162-6.

25. Hashida S, Soh J, Toyooka S, Tanaka T, Furukawa M, Shien K, et al. Presence of the minor EGFR T790M mutation is associated with drug-sensitive EGFR mutations in lung adenocarcinoma patients. Oncol Rep. 2014;32(1):145-52.

26. Lee Y, Lee GK, Hwang JA, Yun T, Kim HT, Lee JS. Clinical likelihood of sporadic primary EGFR T790M mutation in EGFR-mutant lung cancer. Clin Lung Cancer. 2015;16(1):46-50.

27. Fujita Y, Suda K, Kimura H, Matsumoto K, Arao T, Nagai T, et al. Highly sensitive detection of EGFR T790M mutation using colony hybridization predicts favorable prognosis of patients with lung cancer harboring activating EGFR mutation. J Thorac Oncol. 2012;7(11):1640-4.

28. Richer AL, Friel JM, Carson VM, Inge LJ, Whitsett TG. Genomic profiling toward precision medicine in non-small cell lung cancer: getting beyond EGFR. Pharmgenomics Pers Med. 2015;8:63-79.

29. Zheng Z, Liebers M, Zhelyazkova B, Cao Y, Panditi D, Lynch KD, et al. Anchored multiplex PCR for targeted next-generation sequencing. Nat Med. 2014;20(12):1479-84.

30. Han JY, Kim SH, Lee YS, Lee SY, Hwang JA, Kim JY, et al. Comparison of targeted next-generation sequencing with conventional sequencing for predicting the responsiveness to epidermal growth factor receptor-tyrosine kinase inhibitor (EGFR-TKI) therapy in never-smokers with lung adenocarcinoma. Lung Cancer. 2014;85(2):161-7.

31. Kim HS, Sung JS, Yang SJ, Kwon NJ, Jin L, Kim ST, et al. Predictive efficacy of low burden EGFR mutation detected by next-generation sequencing on response to EGFR tyrosine kinase inhibitors in non-small-cell lung carcinoma. PLoS One. 2013:8(12):e81975.

32. Wang Z, Chen R, Wang S, Zhong J, Wu M, Zhao J, et al. Quantification and dynamic monitoring of EGFR T790M in plasma cell-free DNA by digital PCR for prognosis of EGFR-TKI treatment in advanced NSCLC. PLoS One. 2014; 9(11):e110780.

33. Zhang J, Fujimoto J, Zhang J, Wedge DC, Song X, Zhang J, et al. Intratumor heterogeneity in localized lung adenocarcinomas delineated by multiregion sequencing. Science. 2014;346(6206):256-9.

34. Yatabe Y, Matsuo K, Mitsudomi T. Heterogeneous distribution of EGFR mutations is extremely rare in lung adenocarcinoma. J Clin Oncol. 2011; 29(22):2972-7.

35. Melosky B. Review of EGFR TKIs in metastatic NSCLC, including ongoing trials. Front Oncol. 2014;4:244.

36. Puente XS, Velasco G, Gutierrez-Fernandez A, Bertranpetit J, King MC, LopezOtin C. Comparative analysis of cancer genes in the human and chimpanzee genomes. BMC Genomics. 2006;7:15.

37. Dumont P, Leu Jl, Della Pietra 3rd AC, George DL, Murphy M. The codon 72 polymorphic variants of p53 have markedly different apoptotic potential. Nat Genet. 2003;33(3):357-65.

38. Sullivan A, Syed N, Gasco M, Bergamaschi D, Trigiante G, Attard M, et al. Polymorphism in wild-type p53 modulates response to chemotherapy in vitro and in vivo. Oncogene. 2004;23(19):3328-37.

39. Pim D, Banks L. p53 polymorphic variants at codon 72 exert different effects on cell cycle progression. Int J Cancer. 2004;108(2):196-9.

40. Ferrara N, Gerber HP, LeCouter J. The biology of VEGF and its receptors. Nat Med. 2003:9(6):669-76.

41. Wang Y, Zheng Y, Zhang W, Yu H, Lou K, Zhang Y, et al. Polymorphisms of KDR gene are associated with coronary heart disease. J Am Coll Cardiol. 2007;50(8):760-7

42. Glubb DM, Cerri E, Giese A, Zhang W, Mirza O, Thompson EE, et al. Novel functional germline variants in the VEGF receptor 2 gene and their effect on gene expression and microvessel density in lung cancer. Clin Cancer Res. 2011;17(16):5257-67.

43. Heinrich MC, Corless CL, Demetri GD, Blanke CD, von Mehren M, Joensuu H, et al. Kinase mutations and imatinib response in patients with metastatic gastrointestinal stromal tumor. J Clin Oncol. 2003;21(23):4342-9.

44. Goncalves A, Monges G, Yang Y, Palmerini F, Dubreuil P, Noguchi T, et al Response of a KIT-positive extra-abdominal fibromatosis to imatinib mesylate and KIT genetic analysis. J Natl Cancer Inst. 2006;98(8):562-3.

45. Seinfeld J, Kleinschmidt-Demasters BK, Tayal S, Lillehei KO. Desmoid-type fibromatoses involving the brachial plexus: treatment options and assessment of c-KIT mutational status. J Neurosurg. 2006;104(5):749-56.

46. Dufresne A, Alberti L, Brahmi M, Kabani S, Philippon H, Perol D, et al. Impact of KIT exon $10 \mathrm{M} 541 \mathrm{~L}$ allelic variant on the response to imatinib in aggressive fibromatosis: analysis of the desminib series by competitive allele specific Taqman PCR technology. BMC Cancer. 2014;14:632.

47. Foster R, Byrnes E, Meldrum C, Griffith R, Ross G, Upjohn E, et al. Association of paediatric mastocytosis with a polymorphism resulting in an amino acid substitution (M541L) in the transmembrane domain of c-KIT. Br J Dermatol. 2008;159(5):1160-9.

48. Inokuchi K, Yamaguchi H, Tarusawa M, Futaki M, Hanawa H, Tanosaki S, et al. Abnormality of c-kit oncoprotein in certain patients with chronic myelogenous leukemia-potential clinical significance. Leukemia. 2002;16(2):170-7.

49. Siegelin MD, Borczuk AC. Epidermal growth factor receptor mutations in lung adenocarcinoma. Lab Invest. 2014;94(2):129-37. 